\title{
The Significance of the Reflective Practitioner in Blended Learning
}

\author{
Aleksej Heinze, University of Salford, UK \\ Chris Procter, University of Salford, UK
}

\begin{abstract}
This paper examines the introduction of blended learning on a part-time higher education programme for mature students. The interpretive work draws on four action research cycles conducted over two years with two student cohorts. Discussion is based on observations, staff and student focus groups and interviews examining the students' expectations and experiences. The initial focus of the action research was on the introduction of technology into the teaching and learning experience. However, the advantage of an interpretive approach is allowing the findings to determine the course of the research. During the first action research cycles, the focus of the research changed from the use of technology in blended learning to the role of the practitioners involved. The authors advocate the key role of reflective practitioners in facilitating blended learning and suggest that action research is a useful framework.
\end{abstract}

Keywords: $\quad$ Action Research, Asynchronous Communications, Blended Learning, Educational Technology Implementation, Electronic Learning (E-Learning), Teacher Improvement, Teacher Preparation

\section{INTRODUCTION}

The United Kingdom (UK) Government has recently decided to shift its emphasis from getting $50 \%$ of 17 to 30 year olds into higher education to educating the overall workforce (Gill, 2008). This results in the targeting of those in work who are willing to engage in higher education, and is in line with international developments where adults have to continue developing in order to remain competitive in the global world economy. In the UK, the move to

DOI: $10.4018 / \mathrm{jmbl} .2010040102$ target the labour market as a source for education is exemplified by the "Higher Education at Work" consultation document (Department for Innovation Universities \& Skills, 2008). This document outlines some of the key challenges facing part-time students, who tend to be adult workers and have families and other commitments:

Employees have to balance commitments with work and family. But research suggests there are almost two million people in the labour market potentially prepared to access higher education. Higher education providers must 
develop new ways of working if they are to meet the potential market from employers and employees... (Department for Innovation Universities \& Skills, 2008, p. 7)

The consultation document also acknowledges that higher education providers mustadapt to the "new customer" and offer educational routes to engage with the potential market of employers and employees. Furthermore, there is a need for "demand-led skills" meeting the needs of individuals and employers (Lord Leitch, 2006). This political landscape inevitably demands continual development of higher education programmes.

One of the attractive methods of delivery that lends itself to part-time student education is blended learning (Heinze \& Procter, 2008; Procter, 2003). Blended learning is often associated with flexibility for the learner whilst offering a structure that provides students with time frames and deadlines to manage their learning process. The flexibility is apparent in the reduced need for attendance at long faceto-face sessions, removal of associated travel to and from these sessions, and in the increased use of e-learning tools to facilitate the student learning process. Blended learning can offer advantages in comparison to learning which is exclusively by distance (i.e. distance learning) or exclusively online (i.e. e-learning). By retaining face-to-face sessions, blended learning programmes may allow more development of social learning, a sense of community and related student-student support and staff-student personal support (Heinze, 2008; Heinze \& Procter, 2006).

Despite the growing significance of blended learning, there is little in the way of programme wide research, a gap that this work attempts to address. The main question this research seeks to address is - What are the critical success factors of blended learning implementation?

This study relies on data source triangulation of both staff and students' observations of a programme, focus groups and semi-structured interviews, thus enabling a critical appraisal of the practice and theory of blended learning.

This paper is structured as follows: first, we examine the literature that highlights the role of blended learning and how it impacts on the associated pedagogy. Second, an overview of the research method will be provided including the context within which a programme was developed. Third, data findings are outlined and discussed in relation to the literature. Finally, conclusions are drawn, limitations of the study are highlighted and future work in this area is suggested.

\section{FINDINGS FROM THE LITERATURE}

\section{Blended Learning}

Blended learning has existed for many years, where face-to-face sessions have been complemented with communication tools such as radio, telephone and television. Over the last ten years, as a result of mass access to the Internet, blended learning has begun to make a major impact on higher education. This impact has been supported by educational technologies such as Content Management Systems, for example Blackboard or Moodle, that enable a "Virtual Learning Environment", where facilitators and students can interact and learn online. The interaction and learning activities are further enhanced by Web 2.0 tools such as wikis that allow a more efficient content creation process when compared to technologies such as email and discussion boards.

However, there is little research evidence to prove that technology has either a positive or negative impact on learning - Ramage referred to this as the "No significant difference" phenomenon (Ramage, 2001). For this reason, studies that claim to have found a positive impact of technology on learning are always treated with suspicion. For example, student feedback is often used as a tool to evaluate learning and teaching, yet this may not always be a reliable guide. This is because both the impact of a 
positive approach and charisma on the part of the lecturer influence the student's perception of learning (see Alauddin \& Butler, 2004). In the famous "Dr Fox Effect" study (Ware \& Williams, 1975), feedback on what was essentially a meaningless lecture was very positive when the style of the performance was appreciated. Ware and Williams (1975) conclude from this that a positive student evaluation does not necessarily equate with effective learning.

However, blended learning is proclaimed by many to have several benefits when compared to either pure face-to-face or pure online learning. Potentially it can offer the best experience of both the face-to-face and online worlds (Heinze $\&$ Procter, 2006). Some particular examples of blended learning benefits include an increase in the number of students feeling the sense of belonging to a learner community (Rovai \& Jordan, 2004) and an increase in student support and consequently improved student retention rates (Hughes, 2007). On the other hand, there are also the critics who suggest that the promises of blended learning are not fulfilled (Hofmann, 2005) and others who feel that the concept of blended learning is meaningless and requires further studies (Sharpe et al., 2006).

\section{Blended Learning Pedagogy}

Since the introduction of technology usually means changes to the teaching and learning process, it is important to root the work in relevant pedagogic theory. In a review of current pedagogic research it was suggested that constructivist theory was becoming the predominant view influencing "new pedagogy" (Cullen et al., 2002:11). It is not the intention of this work to explore all of the ways in which constructivism could be implemented on a blended learning programme: this is outside of the scope of this research and has been done by others (Heinze et al., 2007). The emphasis of the current work is on the student-student and teacher-student interactions; it is the relationship of these interactions to constructivist theory that are of interest here. Teacher-student interactions are examined in the light of conversational methods and the student-student interactions are examined in the light of the social theories of learning. In doing this, one is aware that pedagogic theories can be "...joined up as compatible sub-themes" (Mayes, 2007, p. 84). Constructivists, particularly social constructivists, recognise the individuality of learners and their social nature. Thus, individuals are at the centre of the learning process and teachers are there to facilitate their learning. The term facilitator (instead of teacher or tutor as above) is therefore utilised to denote the constructivist nature of learning.

The theory developed in the Conversational Framework (Laurillard, 2002) is specifically concerned with interaction between facilitators and students. This work is widely recognised as a major influence on the pedagogic design of Virtual Learning Environments (Cullen et al., 2002). The Conversational Framework has its roots in Conversation Theory (Pask, 1976) and Learning Conversation (Harri-Augstein \& Thomas, 1991), both of which highlight the importance of facilitator-learner interaction in the development of learning. However, although widely cited, the Conversational Framework is rarely used in practice (Dyke et al., 2007), possibly due to practical considerations (Heinze \& Heinze, 2009).

Group dynamics and the study of students in a group have been examined by a number of researchers. One of the key figures in this research is Vygotsky, whose work on the Zone of Proximal Development (ZPD) is of particular importance. Vygotsky argues that if interaction between the learner and the facilitator does not take place, the learner will fail to develop to the level of the facilitator. Using the language of the Zone of Proximal Development (Vygotsky, 1978), the learner can develop only as far as the facilitator is able to challenge them (Heinze et al., 2007).

\section{RESEARCH METHOD}

The underlying philosophical assumptions of our work are interpretive and are based on 
Chua's classification (Chua, 1986). This means that ontologically, we believe that the conclusions are assessed via the criteria of logical reliability and subjective interpretations (Oates, 2006). Moreover, ontologically, reality is subjectively constructed and objectified through human interaction (Chua, 1986). Interpretive action research allows for the creation of change whilst simultaneously studying the effects of this change (Baskerville \& Myers, 2004), and was therefore selected as the research method for this study. Continuously evaluating intervention and associated results and interpretations allows for a better understanding of the situation from different points of view (Miles \& Huberman, 1994). Furthermore, some argue that action research provides the most effective way of engaging academic staff in their continuous development in order to achieve improvement in their educational practice (Biggs, 1999).

Ethics are an important consideration of action research. Formal approval of Ethical Consent for the conduct of this research was granted by the institution's Research Governance and Ethics Sub-Committee and the consent of each participant was secured at all data collection stages.

\section{Data Sources}

Four action research cycles were conducted. Each cycle was one academic semester long. The research looked at one or two groups of students in each cycle. One cycle would involve a process of programme design followed by implementation, data gathering, data analysis, followed by further improvement and development. Data was gathered by participant observation that was triangulated with 8 focus groups, 31 semistructured interviews and other documentary sources. The use of multiple sources of data in this research was designed to guard against the "Dr Fox Effect".

The questions used for the data collection probed the individuals' experience of blended learning on the programme in question. Emphasis was placed on the perceived benefits and drawbacks of blended learning and how the use of blended learning could be improved. Particular attention was paid to the use of time in the face-to-face sessions and to the online interactions. The questions also probed whether blended learning was appropriate for part-time mature students and the reasons underlying this. The data was all transcribed for analysis. The analysis was undertaken using NVivo QSR software. For the whole dataset described above this resulted in 211 nodes and related concepts. At each cycle of the action research the main themes from these results were highlighted and used in discussions by the teaching team.

All students on the programme were invited to attend focus groups and data from these groups were fed back to the staff meetings and staff focus groups. The staff focus groups were open to all academic and support staff involved in the programme. Staff discussed their views, the student focus group data, observations and any other relevant data such as "student exit" statements and as a result of these sessions, actions were agreed.

\section{Research Setting}

Both authors of this paper were involved with the delivery of the current programme. One of the authors was the director of the programme. The second author was a member of support staff, namely a graduate teaching assistant (GTA). Nine members of lecturing staff participated in the interviews represented in this study. Most were Information Communication Technology (ICT) literate with a wealth of lecturing experience. Some had taught in the past using websites to communicate information, and had supported students via email and other technologies. Although the majority had been lecturing for several years, there was still a wide diversity of experience, including staff with less than five years experience and others who were nearing retirement.

There were three support groups directly involved with the programme: administrative staff; technical support and GTAs. The GTAs were postgraduate students and usually there was one GTA and one lecturer allocated per 
module. Of these, six individuals participated in interviews. Several other members of support staffalso participated in the focus groups but are not specifically identified due to their limited input and the complexity of identifying them as individuals in a group discussion.

The study was at the University of Salford at the time of the introduction of a new part-time $\mathrm{BSc}$ in Information Technology programme. Students who enrolled on the programme were predominantly mature $(21+$ years of age) and the majority of them were in full time employment. The nature of their employment varied, with some students already working in the IT industry and wanting to progress to a higher level, and others in different industries wishing to enter the IT domain. The majority did not meet standard BSc entry requirements but had plenty of prior experience and learning. In the first year (cohort 1) of the current research, approximately 40 students enrolled on the programme, in the second year (cohort 2) there were about 20 students. Overall, eight students took part in interviews in this study. The majority of student data however, was collected through focus groups.

The blended learning was implemented as follows: attendance was required for one 3.5 to 4 hour face-to-face evening session each week. E-learning elements were facilitated through the Blackboard Virtual Learning Environment (VLE) and other electronic resources such as SkillSoft Learning Objects, external book publisher websites, multiple-choice questions and other electronic tools. Students were also required to engage in self-study including extensive reading on their own, encouraged through a range of individual assignments.

It was agreed that a blended learning approach to programme delivery would be utilised. As such, it was intended that the faceto-face component of the course would be the main opportunity for socialisation. Support for coursework would be available face-to-face as well as virtually. It was agreed that an action research approach to delivery and the development of the programme would be used to allow for continuous improvement. Furthermore, a graduate teaching assistant would be employed to carry out the necessary research. His roles would include: supporting the day-to-day running of particular modules on the programme; supporting students through online, face-toface, telephone and email communication; the support of the administration of Blackboard VLE in all its aspects - the creation of groups, assignments/assessments, moderation of discussion forums and student/staff training; and the evaluation of both student and staff feedback.

\section{FINDINGS AND DISCUSSION}

Four cycles of action research were held. After each cycle (corresponding to a semester of the academic year) research was conducted with both students and staff. The key findings are summarised below .

\section{Benefits of Blended Learning}

Several perceived benefits of the blended learning programme were identified in this work. These included the locality, the time of the sessions and having to attend the physical university premises just once a week.

Some students stated that the social aspects of coming in and seeing people face-to-face each week were the things that made them choose this programme, as illustrated by the following quotes:

I don't know about other people, but I feel like when I haven't done an assignment and then I find out that I am not the only one I feel like yeah... [Gesture of his fist hitting the air]. Student A in Focus Group

Ilooked at other courses at the Open University, but I thought, Imean you meet here once a week ... Student B in Focus Group

I would say what this course offers, that say the Open University doesn't, is the face-to-face meeting, rather than Blackboard itself. Student C interview 
Academic staff also observed the importance of the role of social interaction. This is echoed in the comments from a lecturer on the programme:

You see we have an older bunch of students here and it is partly you know I suppose confidence in your material, but then in terms of what they have learned in terms where did they learn the most, I don't think it would have been in my module, they probably had a bit of a good time, you know and enjoyed a bit of banter. Lecturer A interview

This finding supports earlier work suggesting that blended learning can improve the sense of social community amongst students (Rovai \& Jordan, 2004). It also highlights the impact of social constructivist pedagogy, where students learn and support one another during the process of study. The opportunity for communication offered in face-to-face sessions is therefore valuable in building social support and student confidence, which might be more difficult in online communication. This also helps others developing blended programmes in using the face-to-face time for social interaction activities such as in-class discussions, group activities and brainstorming tasks. The key purpose of the face-to-face time is to "bond" the students and make them feel at ease with each other. This time could be used for example for researching and delivering a group presentation or peer evaluation of others work.

Moreover, the face-to-face session attendance was also beneficial for structuring learning and developing a learning routine for students. This is evident from observations and students' comments expressing the importance of attendance in imposing a discipline to their learning:

There was also a positive feeling of structure to the programme imposed by assignment submission deadlines and weekly attendance. Student $F$ in Focus Group
It was difficult [referring to a fully online course] but here we come in, we get our assignment and we have time to do it. There is more structure to it. Student G in Focus Group

Generally, they felt that blended learning was suited to part-time students. Similar findings are reported on other courses where student support was improved due to the use of blended learning (see Hughes, 2007). Our findings suggest that the weekly face-to-face evening sessions encouraged a student learning routine and are a reasonable practical commitment for mature students. The vast majority of them have successfully time managed their working life, social and family commitments with studying on the current part time programme.

\section{Communication}

A number of issues were raised in relation to communication between students, and the limitations of electronic communication as far as they saw it. Despite the positive observations of some students about the benefits offered by the social interaction in the face-to-face time, as mentioned in the section above, there were some who felt that more social time was needed between students:

There are still some areas that can be improved, in particular on the social side of things [...]. I know that students were trying to organise a social [...] but it did not happen. Student H in Focus Group

Students also discussed (in the following passage) the difficulty of discussing problems (online) with their learning:

What would happen with our full time students is that they would have a lecture, they would listen to the lecturer and they would go away to the canteen and they would talk about what was said in the lecture and somebody would say - I didn'tunderstand that. Did anybody understand that bit about whatever? And they would talk about that. And somebody would say well I have 
done that bit before and this is what it means, and they would explain to each other and they re-enforce it. Do you get an opportunity to do that? Lecturer P in Focus Group

We have not been using (the discussion board) to discuss it in that way. It was not used to bounce ideas of each other it was more like if somebody has got a problem then Student J in Focus Group

You don't want to look stupid I think Student K in Focus Group

\section{[laughter]}

Yes, you have to be brave to be able to say I am the first one and I didn't understand that Student J in Focus Group

Yeah, it is just getting the confidence in using it Student K in Focus Group

Yeah, but I think that we expected it to happen and we have not seen it happening. Student J in Focus Group

These students clearly expected a greater level of communication online and were disappointed with the provision facilitated as part of this blended learning programme.

The predominant communication tool used was an asynchronous discussion board. In addition to the issue raised above, concerning confidence with using the discussion board, another drawback was that students were not sure if they should reply to messages that were a couple of days old:

... you know that we are all part-time and we can't access the discussion boards at the same time so you are finding yourself answering questions that are two or three days out of date. For example, if you are looking at things and you see [Name] asking a question and you think "oh I know what you should do but then you think oh it is three days ago, they probably know the answer". Student L in Focus Group

Although students were encouraged to reply to old messages, it was difficult for some of them to get quick responses. The informal agreement was that the GTAs would check the online discussion boards at least every other day. This research predates the widespread use of RSS (Really Simple Syndication) feeds and email notification updates for students and staff, which make it easier to ensure timely responses. Furthermore, wikis have been introduced much more widely into teaching since the research was conducted. However, the introduction of new tools emphasises the importance of the facilitator regularly using the tools they provide for the students, to keep discussions active. We argue therefore that it is the facilitators who always have to listen to their students and adapt to the programme needs. This raises the need for reflective practitioners, which was facilitated through the action research cycles and continues with learner observations and feedback from the learners.

\section{Staff Development and Autonomy}

The research highlighted one of the underlying difficulties in implementing proposed actions: namely academic staff autonomy and a resistance to change or learn to from the mistakes of others. The above comments about the communication issues were identified early on in the first action research cycles and the summary of the actions were communicated to the staff taking over in the subsequent semesters. However, not many of these new staff were engaged in the learning from their peer evaluation process.

For example, a guide to the effective use of the Blackboard VLE, incorporating lessons learned through the first cycle of action research, was emailed to all staff involved in the programme. Staff were given the opportunity to attend programme meetings and away days. There were many positive observations from staff who did attend these sessions and engaged in dialogue and learning with colleagues and 
implemented the observations of others in their teaching. One of these examples was the implementation of a standard navigation bar for all modules on the Blackboard VLE:

You know literally some lecturers have had twelve options down the left hand side. It was trimmed down to four or five options. Lecturer $D$ in Staff Focus Group

However, interest in these events varied and despite the action research framework adopted by the core team of the programme, not everyone engaged in the action research fully, hence the lessons learned were not taken on board by everyone. One member of staff felt that the change in a lecturer's development was slow and therefore required time so that all staff could manage to implement their own lessons learned:

Well I think that lecturers have learned, ... they are developing themselves slowly...the individual tutors are autonomous and therefore they will do what they want to do and there is not much that can be done about that. Lecturer $K$ interview

The mode of delivery was a challenge that was highlighted by a number of lecturers and one of these emphasised the required changes to their practice:

I think for the lecturers the biggest issue is changing their mode of delivery. Because this course is different to courses which most lecturers have been used to teaching on. For example, the standard mode of delivery now in most Higher Education [institutions] is PowerPoint lectures, I don't know what proportion but the great proportion of lecturers in this university and elsewhere use PowerPoint lectures and then they may have seminars to support that. But that mode in my opinion doesn't really suit Blended Learning so... That means that there is quite a lot of work for lecturers to do to actually develop that. A lot of thinking in terms of designing their teaching and learning. Lecturer $F$ interview

Another lecturer discussed how they had enjoyed adapting their practice:

Well I have enjoyed teaching, or helping the part time students to learn, as against teaching, because it was far more interactive. I think it was a critical point, in the sense that it wasn't as much teaching as prompting debate and discussion and putting some theoretical points forward and asking them what is your experience, do you think this model or concept is flawed, justify your critique of this model or theory, you can't just criticise. So it was the interaction that I enjoyed. Lecturer $K$ in interview

Some were unwilling to change their teaching style at all:

...but I have always taught like that for the last 30, 40 years and that is the way that most people that started in my era actually teach. Lecturer Y interview

Generally, those staff who neither participated in the staff development activity nor engaged in the action research, did not adapt their teaching style to accommodate the new requirements of students on a blended learning programme. The issue of academic staff development was identified as one that could not be easily resolved and past experience and lack of enthusiasm for change was highlighted by many as is illustrated in this quote:

To be fair, we did try and do something like that last time but none of the staff would come, would they? Lecturer D in Staff Focus Group

Some staff argued that they were not reluctant to learn per se, but they did not like the process of going away and discussing issues in a focus group. They felt that it was a matter of individuals going through a process of learning from their own personal experi- 
ence, rather than relying on the observations and experiences of colleagues. This process of personal development goes directly against the social constructivist pedagogic beliefs such as the Zone of Proximal Development and any other conversation theory related practices. How could professionals teach others if they themselves don't like to learn in a collective way? Little evidence was found in our research that this individual approach led to effective change, or that there was significant engagement from such staff with the research literature on teaching and learning in higher education.

The difficulties in developing the practice of academic staff are commonly recognised (Wilson \& Stacey, 2003). For example, Biggs (1999) argues that attending staff development workshops is not a sustainable staff development process, since after the post-workshop enthusiasm wears off, staff are likely to revert to their previous teaching styles. Some argue that action learning offers a good basis for staff development (Ellis \& Phelps, 2000). Staff centred approaches such as continuing professional development and approaches such as action research, that see teaching as continuous research (Biggs, 1999) are presented as being more able to allow staff to keep up-to-date with change and allow them to continuously improve their teaching. Thus, it is suggested that peer observation, where colleagues observe each other's sessions and reflect on the practice, is a valid and useful way of encouraging staff development (Kohut et al., 2007). However, our data suggests that it depends on the individuals and whether they engage with the research process or not. It was found that those engaging in action research and willing to learn and develop their practice were able to benefit both themselves and their students.

\section{Staff Charisma and Enthusiasm}

The role of charisma and an individual lecturer's qualities and rapport with their students was highlighted in all action research cycles. One main issue was that the individuals who taught or facilitated sessions were important:
I was given a PowerPoint presentation ... but the personality of that person who did that material is not going to be present. Now if I injected something else in there, that is small, something humorous, but it distracts, it lightens it up and makes it easier to go through.[...] Humour is a fantastic tool in learning. Support Staff A interview

It is difficult, because they have to a) know their stuff and b) be enthusiastic about it. Otherwise students are going to think hell he[/she] is boring, I am going to sleep now. Lecturer $H$ interview

This individual staff charisma and enthusiasm was also prominent when students were asked about their impressions of individual modules. One observation made by several students was that an important part of a module's success was related to the individual lecturer. The question "what is it that makes a module either a good module or a less desirable one?" attracted the following reply:

The lecturer. I think [...] was good on that score certainly. Student L interview

The issue of individual lecturers being responsible for the learning experience was evident in one case where a student felt that a member of staff was lazy and that this dictated their module delivery:

With [Name], all our people are convinced that this guy wants us to pass. Having said that he is lazy, he wants us to pass because he is lazy, it is more difficult to fail a student than to pass them. [laughter]. They do agree that he seems to be on our side. [laughter]. Student G interview

Whether or not staff enthusiasm was linked to student success was not measured in the research and would be a valuable component of future research in blended learning. However, findings in the current blended learning study support earlier work done on the Dr Fox Effect. 
This again underlines the need for academic staff to engage with their peers in developing their teaching practices. Otherwise, if the only measure for student success is student feedback - we realise that those staff who treat their students well but don't engage in teaching them can still get good feedback. This finding also suggests that any blended learning evaluation study must take into account the measure of the staff perceptions and peer reviews instead of relying on students' views only. Yet again, this finding would not have surfaced if the action research method was not adopted in the current study.

\section{CONCLUSION}

The findings in this study suggest that blended learning is valuable to part-time students in combining work and study. In particular, our findings support earlier studies that show a relationship between blended learning and students' sense of community. Face-to-face contact can offer social advantages in comparison to a virtual course and thus sessions should be designed to allow students time to socialise with one another.

However, the extent to which the learning advantages are achieved is dependant upon the engagement of stakeholders in the mode of delivery - this is the main finding to our research question aiming to identify critical success factors of blended learning implementation. Our reflections on the use of action research have allowed us to re-consider the overall teaching and learning process. In particular, the need for interaction between the learner and the facilitator was identified, and a key variable that made a difference in the student learning experience was found to be the facilitator. The level of engagement of academic staff in blended learning is key to the success of this mode of delivery. Some staff were reluctant to engage with others on either a formal (e.g. staff development activity) or informal basis, and this limited the effectiveness of blended learning that was facilitated by them. Vygotsky's concept of the Zone of Proximal Development is relevant, suggesting that those staff who actively engage with others in a continuous process of reflection and development are more likely to improve their practice in the context of new methods of teaching and learning. Those who engage in the Zone of Proximal Development are more likely to benefit from the common knowledge. Thus, a vital element in the introduction of blended learning is the ability of the facilitator to see teaching as a continuous process, building on peer interaction. The introduction of effective blended learning on a part time programme does not fit with a didactic approach of teaching. Our evidence suggests that a project to implement blended learning needs to start with a process of facilitating the facilitators.

We haven't researched the best ways to do this but brief suggestions are given below. Potentially, staff could introduce the concept of the critical friend to help each other to improve: mentoring and peer-observation may enhance the level of reflection and engagement more effectively than wholesale staff training. This process can be developed further by regarding teaching as research, as suggested by Biggs (1999). This builds in critical reflection and opportunities for external critique for colleagues by presenting their work at conferences and in peer reviewed publications. Action research is a valuable method in introducing and reflecting upon change but on its own does not guarantee peer interaction.

Our findings are aimed at anyone involved in blended learning programme developments, implementation and improvement and are independent of the particular form of technology used. Clearly, they are limited in their generalisation due to the method used, the relatively small data sample, and the use of just one programme in one institution. Furthermore, the interpretive action research concentrated on the process of teaching and learning and not the outcomes. We suggest that further studies in this area be undertaken. Further research could broaden the data sample to compare programmes or institutions. This could follow our findings investigating how facilitators adapt (or not) to the use of blended learning in higher education. 
It would also be valuable to investigate how best to facilitate the facilitator. Furthermore, future research could be advanced by investigating the pedagogic design of blended learning in practice. In particular, we need to investigate how support for socialisation and communication is best provided within blended learning. In this way future action research in blended learning can address the process of introducing technology into teaching and learning alongside the consequent (and changing) learning outcomes.

\section{ACKNOWLEDGMENT}

The authors would like to acknowledge and thank the action research collaborators comprising staff and students involved in the BSc Information Technology at the Salford Business School, University of Salford. The programme received support through the European Social Fund project "Flexible IT for workers". The ideas for this paper were further developed at the Annual Blended Learning Conference 2008 at the University of Hertfordshire. We would also like to thank the anonymous reviewers of the International Journal of Mobile and Blended Learning for their constructive and helpful comments.

\section{REFERENCES}

Alauddin, M., \& Butler, J. E. (2004). Teaching economics in a changing university environment: Some Australian experience. International Journal of Social Economics, 31(7), 706-720. doi:10.1108/03068290410540891

Baskerville, R., \& Myers, M. D. (2004). Special issue on action research in information systems: making is research relevant to practice- foreword. Management Information Systems Quarterly, 28(3), 329-335.

Biggs, J. (1999). Teaching for quality learning at university: what the student does. Buckingham, UK: Open University Press.

Chua, W. (1986). Radical Developments in Accounting Thought. Accounting Review, 61, 601-632.
Cullen, J., Hadjivassiliou, K., Hamilton, E., Kelleher, J., Sommerlad, E., \& Stern, E. (2002). Review of current pedagogic research and practice in the fields of post-compulsory education and lifelong learning (Report). London: The Tavistock Institute.

Department for Innovation Universities \& Skills. (2008). Higher Education at Work-High Skills: High Value. Sheffield, UK: Author.

Dyke, M., Conole, G., Ravenscroft, A., \& De Freitas, S. (2007). Learning theory and its application to e-learning . In Conole, G., \& Oliver, M. (Eds.), Contemporary perspectives in e-learning research (pp. 82-97). London: Routledge.

Ellis, A., \& Phelps, R. (2000). Staff development for online delivery: a collaborative team-based action learning model. Paper presented at the Australasian Society for Computers in Learning in Tertiary Education, Brisbane, Australia.

Gill, J. (2008, April 17). Labour concedes that it won't deliver its 50\% target on time. Times Higher Education, 14.

Harri-Augstein, S., \& Thomas, L. F. (1991). Learning Conversations. London: Routledge.

Heinze, A. (2008). Blended learning: an interpretive action research study. Unpublished $\mathrm{PhD}$ Thesis, University of Salford.

Heinze, A., \& Heinze, B. (2009). Blended E-Learning Skeleton of Conversation: improving formative assessment in undergraduate dissertation supervision. British Journal of Educational Technology, Special Issue: e-Assessment: developing new dialogues for the digital age, 40(2), 294-305.

Heinze, A., \& Procter, C. (2006). Online Communication and Information Technology Education. Journal of Information Technology Education, 5, 235-249.

Heinze, A., \& Procter, C. (2008). Is Blended Learning a 'silver bullet' for part-time mature student education? Paper presented at the Blended Learning Conference 2008. Retrieved from http://www.herts. ac.uk/fms/documents/teaching-and-learning/blu/ conference2008/Aleksej-Heinze-2008.pdf

Heinze, A., Procter, C., \& Scott, B. (2007). Use of Conversation Theory to underpin Blended Learning. International Journal of Teaching and Case Studies, 1(1-2), 108-120. doi:10.1504/IJTCS.2007.014213 
Hofmann, J. (2005). Why blended learning hasn't (yet) fulfilled its promises: Answers to those questions that keep you up at night. In Bonk, C. J., \& Graham, C. R. (Eds.), The Handbook of Blended Learning: Global perspectives (pp. 27-40). San Francisco: Pfeiffer.

Hughes, G. (2007). Using blended learning to increase learner support and improve retention. Teaching in Higher Education, 12(3), 349-363. doi:10.1080/13562510701278690

Kohut, G. F., Burnap, C., \& Yon, M. G. (2007). Peer Observation of Teaching: Perceptions of the Observer and the Observed. College Teaching, 55(1), 19-25. doi:10.3200/CTCH.55.1.19-25

Laurillard, D. (2002). Rethinking university teaching: A framework for the effective use of educational technology (2nd ed.). London: Routledge/Falmer. doi:10.4324/9780203304846

Lord Leitch. (2006). Prosperity for all in the global economy - world class skills. London: HM Treasury.

Mayes, T. (2007). Learning theory and its application in e-learning. In Dyke, M., Connole, G., Ravenscroft, A., \& de Freitas, S. (Eds.), Contemporary perspectives in e-learning research: themes, methods and impact on practice. London: Routledge.

Miles, M., \& Huberman, M. (1994). Qualitative Data Analysis: An Expanded Sourcebook. London: Sage Publications.

Oates, B. J. (2006). Researching Information Systems and Computing. London: Sage Publications.
Pask, G. (1976). Conversational techniques in the study and practice of education. The British Journal of Educational Psychology, 46, 12-25.

Procter, C. (2003). Blended Learning in Practice. Paper presented at the Inaugural Education in a Changing Environment conference, Salford, UK.

Ramage, T. R. (2001). The "No Significant Difference" Phenomenon: A Literature Review. Journal of Instructional Science and Technology (e-JIST), 5(1).

Rovai,A.P., \& Jordan, H. M. (2004,August). Blended Learning and Sense of Community: A Comparative Analysis with Traditional and Fully Online Graduate Courses. International Review of Research in Open and Distance Learning.

Sharpe, R., Benfield, G., Roberts, G., \& Francis, R. (2006). The undergraduate experience of blended e-learning: a review of UK literature and practice. Higher Education Academy.

Vygotsky, L. (1978). Mind in Society; The development of Higher Psychological Processes (Cole, M., John-Steiner, V., Scriber, S., \& Souberman, E., Trans.). Cambridge, MA: Harvard University Press.

Ware, J. E. J., \& Williams, R. G. (1975). The Dr. Fox effect: a study of lecturer effectiveness and ratings of instruction. Journal of Medical Education, 50(2), 149-156.

Wilson, G., \& Stacey, E. (2003, December 7-10). Online interaction impacts on learning: teaching the teachers to teach online. Paper presented at the Australasian Society for Computers in Learning in Tertiary Education(ASCILITE), Adelaide, Australia.

Aleksej Heinze is a senior lecturer in the Salford Business School, University of Salford, UK. His research interests are in blended learning, management education and Enterprise 2.0.

Chris Procter is a senior lecturer in the Salford Business School, University of Salford, UK. His research is primarily into teaching and learning and especially blended learning. 